\title{
Diseño del proyecto ecoturístico Shalcani y valoración de impactos ambientales durante la fase constructiva, Misahuallí, Napo
}

\section{Ecotourism project design and assessment of environmental impacts in the construction phase, Misahualli, Napo}

\author{
Aída Arteaga Mena ${ }^{1}$, Estefanía Segarra $^{1}$ \\ ${ }^{1}$ Universidad Central del Ecuador. Facultad de Ciencias Agrícolas. Carrera de Turismo Ecológico. \\ Jerónimo Leiton y Av. La Gasca s/n. Ciudadela Universitaria. Quito. 170521. Ecuador
}

\begin{abstract}
Resumen
El proyecto ecoturístico Shalcani está ubicado en la parroquia Misahuallí, provincia de Napo. Se condujo un amplio estudio con el propósito de examinar los potenciales efectos ambientales durante la fase constructiva del proyecto y explorar la eventual acogida turística. El presente artículo reporta solamente los potenciales impactos ambientales de la construcción del proyecto. La investigación contempla cuatro objetivos específicos: (i) diseñar el proyecto eco-turístico; (ii) realizar el diagnóstico ex ante; (iii) identificar y valorar los impactos ambientales; y (iv) elaborar medidas de manejo ambiental. El diagnóstico ambiental ex ante posibilitó la identificación de potenciales impactos ambientales utilizando técnicas de observación, entrevistas y una amplia investigación documental. La valoración de los impactos ambientales obtenidos en el estudio se distribuyeron en una matriz de doble entrada que toma en cuenta las causas (acciones impactantes) y los efectos (componentes abiótico, biótico y socioeconómico-cultural) bajo los criterios de magnitud e importancia. Se determinó que las acciones impactantes de mayor relevancia corresponden a la tala de bosque, desbroce de la cobertura vegetal, construcción de senderos y transporte de materiales de construcción. Los receptores ambientales mayormente afectados corresponden al paisaje, suelo, fauna, flora y aire. Se destaca el receptor ambiental socioeconómico-cultural como beneficiario del proyecto. La valoración de impactos cuantifica 48 impactos negativos, de los cuales, 20 son de intensidad media y de magnitud baja, 20 impactos de intensidad permanente de baja magnitud y 8 impactos de afectación mínima y 10 impactos positivos de trascendencia y magnitud media, puntual y local. Sobre la base de los hallazgos de la valoración se sugieren las medidas de manejo ambiental que se focalizan prioritariamente en el área de mitigación de impactos.
\end{abstract}

Palabras clave: línea base, medioambiente, matrices, área, medidas ambientales.

\begin{abstract}
The Shalcani ecotourism project is located in the Misahualli parish, Napo province. An ample study was conducted to examine the potential environmental effects during the construction phase and to explore the possible tourist reception. This article reports only the environmental effects of the construction phase of the project. The research includes four specific objectives: (i) to design the eco - tourism project; (ii) to make the diagnosis "ex ante"; (iii) to identify and assess the environmental impacts; and (iv) to develop environmental management strategies. The "ex ante" environmental assessment enabled the identification of potential environmental impacts using observation techniques, interviews and extensive documentary research. The assessments of environmental impacts were introduced in in a double entry matrix which takes in account the causes (impact actions) and its effects (abiotic, biotic and socioeconomic - cultural components) under the criteria of magnitude and significance. The most relevant impact actions were forest logging, vegetation cover clearing, trail construction and transportation of building materials. The environmental receptors most affected were landscape, soil, fauna, flora and air. The socioeconomic-cultural environmental receptor was found beneficiary of the project. Impact assessment quantified 48 negative impacts, 20
\end{abstract}


of them were of medium intensity and low magnitude, 20 of permanent intensity and low magnitude, 8 of minimal affectation, and 10 positive local impacts of medium magnitude and significance. Based on the assessment findings, environmental management measures were suggested focused primarily on the area of impact mitigation.

Keywords: baseline, environment, matrix, area, environmental measures.

\section{Introducción}

En las últimas décadas, resulta inquietante la acelerada intervención del ser humano en el entorno sin observar básicos principios de conservación, situación que ha promovido el deterioro e incluso la degradación de importantes ecosistemas marinos y terrestres. La Amazonia ecuatoriana ha sido escenario de múltiples intervenciones de gran envergadura como la explotación petrolera, la explotación minera a gran escala y la deforestación al servicio del mercado maderero (Izko, 2012), pero también existen múltiples injerencias locales, dentro de las cuales destaca la conversión del uso de la tierra hacia actividades agrícola-ganaderas, como ejemplo de un manejo poco amigable del ambiente (Vera \& Riera, 2001).

De otra parte, el Ecuador se ubica en el sexto lugar a nivel mundial en megadiversidad (Mittermeier et al., 1997), lo que posibilita explorar un amplio nicho para el bio-conocimiento, entendido como aquel que procede de los saberes ancestrales, así como también aquel que se deriva de la investigación científica, conocimientos que sentarán las bases para el aprovechamiento racional de los recursos, apuntalando de manera efectiva el desarrollo sostenible (Villavicencio, 2011).

En este contexto, este trabajo de investigación tiene como objetivo examinar los potenciales efectos ambientales durante la fase constructiva el proyecto ecoturístico en la parroquia Misahuallí, provincia amazónica de Napo y explorar el potencial de acogida turística, en especial del turismo científico. El presente artículo hará especial referencia al tema ambiental. La investigación contempla los siguientes objetivos específicos: (i) diseñar el proyecto ecoturístico; (ii) realizar el diagnóstico ex ante del área de influencia directa del proyecto; (iii) identificar y valorar los impactos ambientales; (iv) sugerir medidas de manejo ambiental.

\section{Aspectos metodológicos}

El proyecto se emplaza en el sector Shalcana Puni-Venecia, en la parroquia Puerto Misahuallí, provincia de Napo. El sitio está ubicado $27 \mathrm{~km}$ de la ciudad del Tena, en las coordenadas $1^{\circ} 05 " 82$ " S y $77^{\circ} 41 " 15^{\prime \prime} \mathrm{W}$, a una altitud de $450 \mathrm{msnm}$. La infraestructura a implementarse abarca una superficie de alrededor de $10.000 \mathrm{~m}^{2} \mathrm{e}$ incluye cabañas con diseño arquitectónico vernáculo para reflejar las características intrínsecas del entorno y de la cultura del lugar.

El clima del área del proyecto es cálido húmedo tropical, con una precipitación media anual de 2.300 $\mathrm{mm}$, temperatura promedio mensual de $23,9^{\circ} \mathrm{C}$ y 2,1 $\mathrm{m} / \mathrm{seg}$ de promedio mensual de velocidad del viento a las 13 h00 (INAMHI, 2014). El sitio está localizado en un valle fluvial con aluviones y pendientes naturales suaves a planas que no sobrepasan los $15^{\circ}$ de inclinación, el suelo es ácido ( $\mathrm{pH} 4,5)$, arcilloso, poco profundo, de drenaje moderado, pobres condiciones químicas y baja fertilidad natural, según información del Plan para el Buen Vivir y Ordenamiento territorial de la parroquia Misahuallí 2011-2020 (Gobierno Parroquial de Misahuallí, 2011).

Por otro lado, el proyecto se ubica dentro del sistema hídrico del río Shalcani que ofrece buena calidad de agua para las especies vegetales y animales del sector. El río se encuentra en el límite norte del proyecto y durante su recorrido se une al río Puní, afluente del río Arajuno.

Desde el punto de vista de análisis ambiental, la planificación de un proyecto de esta naturaleza debe examinar las fases de construcción, operación y mantenimiento, así como la fase de abandono. La presente investigación reporta únicamente la fase de construcción.

La identificación de los potenciales impactos ambientales se realiza sobre la base de la información sistematizada recolectada durante el diagnósti- 
co ambiental ex ante, para lo cual fue necesario utilizar técnicas de investigación universalmente aceptadas como la observación, la entrevista y una amplia investigación documental.

Considerando el grado de interrelación de las acciones a conducirse para obtener las distintas variables socio-ambientales se determinó el área de influencia directa que define el marco de referencia geográfico en el cual se efectúa el análisis y la valoración ambiental, es decir, el territorio donde potencialmente se manifiestan los impactos ambientales abióticos, bióticos y socioeconómico-culturales, bajo dos criterios: (i) extensión del proyecto; y (ii) totalidad de los componentes ambientales afectados por las acciones impactantes.

De igual manera, se delimitó el área geográfica de influencia indirecta bajo los siguientes criterios: (i) articulación vial directa; (ii) relaciones o flujos directos entre centros poblados y actividades económicas y productivas; y (iii) oferta de mano de obra para abarcar una superficie representativa de $800 \mathrm{~m}$ a la redonda respecto al área de influencia directa del proyecto.

La valoración de impactos se condujo siguiendo la metodología propuesta por Leopold - Páez (Peláez, 2002) utilizando la matriz causa-efecto, bajo los siguientes criterios: (i) magnitud del impacto que califica la intensidad de afectación y el grado de alteración en una escala de 1-10; y, (ii) importancia del impacto definido como la trascendencia, el peso relativo del impacto en relación a su entorno según características de reversibilidad, recuperabilidad, duración, aparición temporal, localización y complejidad del impacto, en una escala de 1-10, atribuyéndose a este criterio la característica de impacto adverso o beneficioso (signo positivo o negativo) para contabilizarse finalmente las interrelaciones positivas y negativas totales del proyecto.

\section{Resultados y discusión}

El escenario donde se implanta el proyecto presenta áreas sin cobertura vegetal primaria, zonas de vegetación secundaria (bosque secundario) y zonas de bosque primario (bosque pluvial). Las áreas deforestadas se destinan a actividades ganaderas, con la implantación de pastizales, y actividades agrícolas con la producción de cultivos como cacao, café, plátano, yuca, maíz duro, naranjilla, entre otros, destinados al autoconsumo y a la venta de excedentes en los mercados locales, en particular del Tena. La descripción de la cobertura vegetal se logró mediante observación in situ, no obstante, es importante indicar que existe una buena correlación con la información reportada por la Secretaría Nacional de Planificación para las unidades ambientales de la zona de Planificación 2 de la parroquia Puerto Misahuallí (Tabla 1).

Tabla 1. Valoración de las unidades ambientales de la parroquia Puerto Misahuallí (Gobierno Parroquial de Misahuallí, 2011).

\begin{tabular}{|c|c|c|c|c|c|c|}
\hline \multirow[b]{2}{*}{$\mathbf{N}^{\circ}$} & \multirow[b]{2}{*}{$\begin{array}{c}\text { Valoración de las } \\
\text { unidades ambientales }\end{array}$} & \multicolumn{5}{|c|}{ Dimensiones de valor } \\
\hline & & Ecológico & Paisajístico & $\begin{array}{l}\text { Científico } \\
\text { cultural }\end{array}$ & Funcional & Productivo \\
\hline \multirow{7}{*}{ 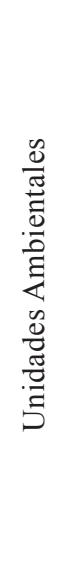 } & $\begin{array}{l}\text { Zonas sin cobertura } \\
\text { vegetal }\end{array}$ & 1 & 2 & 2 & 2 & 3 \\
\hline & Zonas agropecuarias & 3 & 2 & 2 & 2 & 5 \\
\hline & $\begin{array}{l}\text { Zonas de vegetación } \\
\text { secundaria }\end{array}$ & 4 & 4 & 4 & 4 & 3 \\
\hline & $\begin{array}{l}\text { Zonas de bosque húmedo } \\
\text { intervenido }\end{array}$ & 3 & 2 & 2 & 2 & 2 \\
\hline & $\begin{array}{l}\text { Zonas de bosque pri- } \\
\text { mario }\end{array}$ & 5 & 5 & 5 & 5 & 5 \\
\hline & Asentamientos humanos & 1 & 2 & 2 & 2 & 3 \\
\hline & Cuerpos de agua & 5 & 5 & 5 & 5 & 5 \\
\hline
\end{tabular}


La información de la Tabla 1 demuestra que las zonas de bosque primario y cuerpos de agua tienen el valor máximo ambiental (5) y, en consecuencia, son áreas de alta biodiversidad aptas para la implementación de políticas de conservación. Estas son áreas protegidas que corresponden al $35 \%$ del territorio de la parroquia, es decir, 17983 has de un total de 51.380 has.

La flora del área de influencia del proyecto se caracteriza por presentar abundante vegetación natural con un sinnúmero de géneros y especies propias del bosque húmedo tropical. La dinámica de colonización y adjudicación de tierras en la Amazonia ha promovido la intervención antrópica y la explotación de espe- cies maderables finas como Cedro (Cedrela adorata - Meliaceae), Caoba o Ahuano (Swietenia macrophlla - Meliaceae) y Canelo amarillo (Ocotea javitensis Lauraceae), extraídas para la comercialización ilegal y la construcción de viviendas, al punto que la caoba, por ejemplo, casi ha desaparecido de la zona.

La población faunística del área de influencia del proyecto es diversa, pues existen especies de insectos, anfibios y aves con colores, tamaños y características únicas de la Amazonia ecuatoriana. La Tabla 2, además de demostrar la alta diversidad, también describe la fauna de alta demanda para alimentación de colonos y nativos que habitan en el área de influencia del proyecto.

Tabla 2. Fauna del área de influencia directa del Proyecto Shalcani (Albuja et al., 2012).

\begin{tabular}{lll} 
Nombre vulgar & Nombre científico & Estado de conservación \\
\hline Guatusa & Dasyprocta fuliginosa & Preocupación Menor \\
Guanta & Cuniculus paca & Preocupación Menor \\
Chichico & Saguinus graellsi & Vulnerable \\
Chaguamangos - colembas & - & - \\
Pava de monte/ de Spix & Penelope jacquacu & En peligro de extinción \\
Paloma Perdiz Zafiro & Geotrygon saphirina & - \\
Tucán Goliblanco & Ramphastos tucanus & - \\
Cusumbo & Potos flavus & Preocupación Menor \\
Cuchucho & Nasua nasua & Preocupación Menor \\
Venado marrón amazónico & Mazama nemorivaga & Preocupación Menor \\
Saíno & &
\end{tabular}

En el área de influencia del proyecto existen asentamientos humanos periféricos constituidos por una población con identidad kichwa amazónico (Napo Runa) y colonos, la mayoría dedicados a la agricultura, ganadería y comercio de fibra de palma y venta de madera para la elaboración de cajones para fruta (pigue). El mayor ingreso económico proviene de la venta de fibra y productos agrícolas. El estu- dio demostró que las familias en el sector tienen un ingreso promedio de 45 a 85 dólares mensuales que se destinan a alimentación, educación, salud y transporte. Otra actividad que genera ingresos familiares es la explotación artesanal de oro en el río Shalcani y los esteros de la zona (Figura 1), actividad que en los últimos años ha desplazado a la actividad ganadera al conseguir un mayor rédito económico. 


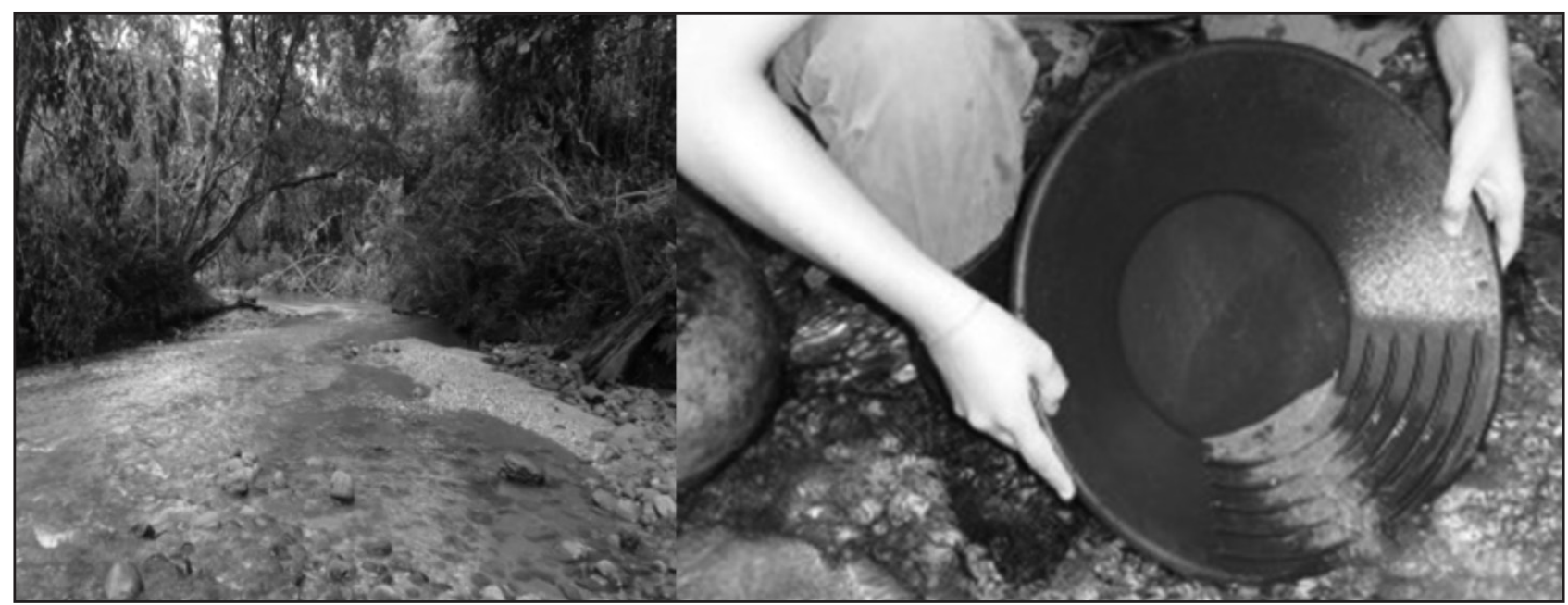

Figura 1. Río Shalcani (foto de Estefanía Segarra) y un ejemplo de bateo de oro artesanal (Asociación Enrique Sanfiz, 2016).

\section{Identificación y valoración de impactos ambientales}

Durante la fase de campo exploratoria-observacional se seleccionó el sitio de emplazamiento del proyecto. Las condiciones del sitio demues- tran que ha existido una alta intervención antrópica que ha dejado áreas de vegetación secundaria o deforestada, pero que no han afectado el bosque prístino del lugar (Figura 2). La ubicación geográfica de las instalaciones propuestas para el proyecto se muestra en la Tabla 3.

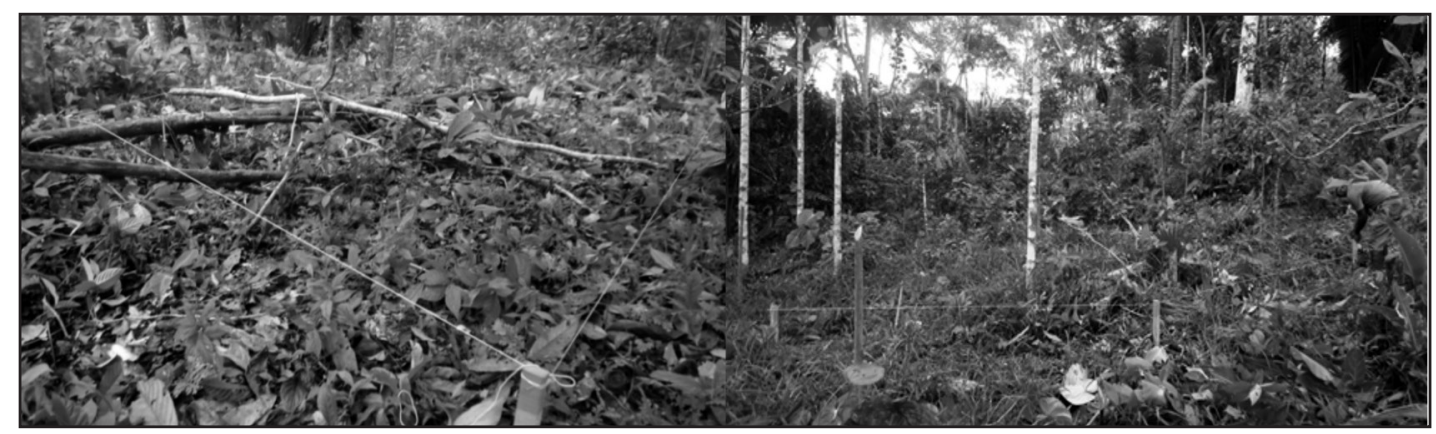

Figura 2. Ubicación para el emplazamiento de la cabaña familiar - vista de ángulo vertical.

Tabla 3. Ubicación de las instalaciones del proyecto eco turístico Shalcani.

\begin{tabular}{lcc}
\multicolumn{1}{c}{ Cabaña } & Latitud & Longitud \\
\hline Recepción & $1^{\circ} 09^{\prime} 48,91 ”$ & $77^{\circ} 69^{\prime} 76,70^{\prime \prime}$ \\
Cabaña cocina/comedor & $1^{\circ} 09^{\prime} 41,78^{\prime \prime}$ & $77^{\circ} 69^{\prime} 64,13^{\prime \prime}$ \\
\hline & Cabañas de alojamiento & \\
\hline Cabaña doble & $1^{\circ} 09^{\prime} 38,70^{\prime \prime}$ & $76^{\circ} 69^{\prime} 58,96^{\prime \prime}$ \\
Cabaña matrimonial & $1^{\circ} 09^{\prime} 37,24 ”$ & $77^{\circ} 69^{\prime} 59,39^{\prime \prime}$ \\
Cabaña familiar/grupos & $1^{\circ} 09^{\prime} 33,99 ”$ & $77^{\circ} 69^{\prime} 63,299^{\prime \prime}$ \\
Cabaña de recreación/mirador & $1^{\circ} 09^{\prime} 38,41^{\prime \prime}$ & $77^{\circ} 69^{\prime} 67,20^{\prime \prime}$ \\
\hline
\end{tabular}


Siguiendo el método de evaluación ambiental propuesto por Leopold-Páez para la identificación de potenciales impactos se procedió a evaluar: (i) los componentes/receptores ambientales que pudieran ser afectados directa e indirectamente por el proyecto durante su construcción; y, (ii) las acciones constructivas que generan dicha afectación. La identificación de los posibles impactos se dividió de la siguiente manera:

\subsection{Identificación de impactos al receptor ambien- tal abiótico}

Se evaluaron los siguientes posibles impactos al receptor ambiental abiótico:

- Aire: alteración de la calidad del aire y generación de olores molestos, incremento en los niveles de ruido.

- Suelo: incremento de la erosión del suelo, disminución de la fertilidad y modificación de la aptitud de uso de la tierra.

- Agua: modificación del caudal del río y deterioro de la calidad de agua.

- Paisaje: modificación del bosque secundario.

\subsection{Identificación de impactos al receptor ambien- tal biótico}

La identificación de los posibles impactos al receptor ambiental biótico se concentran en flora y fauna: pérdida de la masa forestal, modificación de hábitats, alteración de la cadena trófica.

\subsection{Identificación de impactos al receptor socio económico-cultural}

Los impactos a identificarse en el receptor socio económico-cultural son los siguientes:

- Incremento de la sensibilización ambiental.

- Generación de empleo.

- Incremento temporal de la economía local.

- Revalorización de la arquitectura vernácula.

Siguiendo la metodología descrita anteriormente se elaboró la matriz correspondiente (Tabla 4) y se cuantificaron los impactos ambientales. Las acciones de mayor impacto corresponden, en su orden, a la tala de bosque, desbroce general de la cobertura vegetal, construcción de senderos y transporte de materiales de construcción. Los receptores ambientales mayor- mente afectados corresponden, en orden de prioridad, al paisaje, suelo, fauna, flora y el nivel de ruido. Se destaca al receptor ambiental socioeconómico-cultural como ente beneficiario del proyecto.

La valoración de impactos ambientales durante la fase constructiva demostró que se pueden producir 48 impactos negativos, de los cuales, 20 son de intensidad media y de magnitud baja, 20 presentan una intensidad permanente de baja magnitud y $8 \mathrm{im}$ pactos de afectación mínima. Además, cabe mencionar que 10 de los impactos son positivos con trascendencia y magnitud media, puntual y local.

La fase de construcción del proyecto presenta una puntuación negativa total de 238 , situación que refleja la puntual extensión del proyecto y las características bióticas, abióticas y sociales del área de influencia anteriormente descrita. Se destacan las acciones de tala de bosque secundario y desbroce de vegetación como aquellas que mayormente afectan el medioambiente. El proyecto arroja resultados positivos en el componente social con un total de 92 puntos.

La valoración de los impactos permite delinear medidas de manejo ambiental focalizadas en aquellos impactos con valoración altamente negativa, así como medidas que impulsen y estimulen la consecución de mayores beneficios. Un resumen de las medidas de manejo ambiental se presenta a continuación.

\section{Desbroce de la cobertura vegetal y tala de bosque}

- Implementación de protocolos para el desbroce $\mathrm{y}$ tala de bosque.

- Ejecución de una operación de rescate y reubicación de fauna silvestre, si es necesario.

- Implementación de barreras vegetales en el evento de que se afecte la calidad de aire como consecuencia de la generación de polvo.

- Implementación de un plan de reforestación con plantas nativas para favorecer el retorno de animales y mejorar la calidad del aire y la fertilidad del suelo.

- Propiciar la regeneración natural de la vegetación que fue talada durante la construcción.

- Elaboración e implementación de un amplio programa de capacitación sobre la protección de la fauna y flora nativas que inhiban actividades de caza, en particular de aquella fauna en peligro de extinción (pava de monte) y las actividades de explotación maderera. 
Tabla 4. Valoración cuantitativa total de los impactos ambientales en la fase constructiva del proyecto eco-turístico Shalcani.

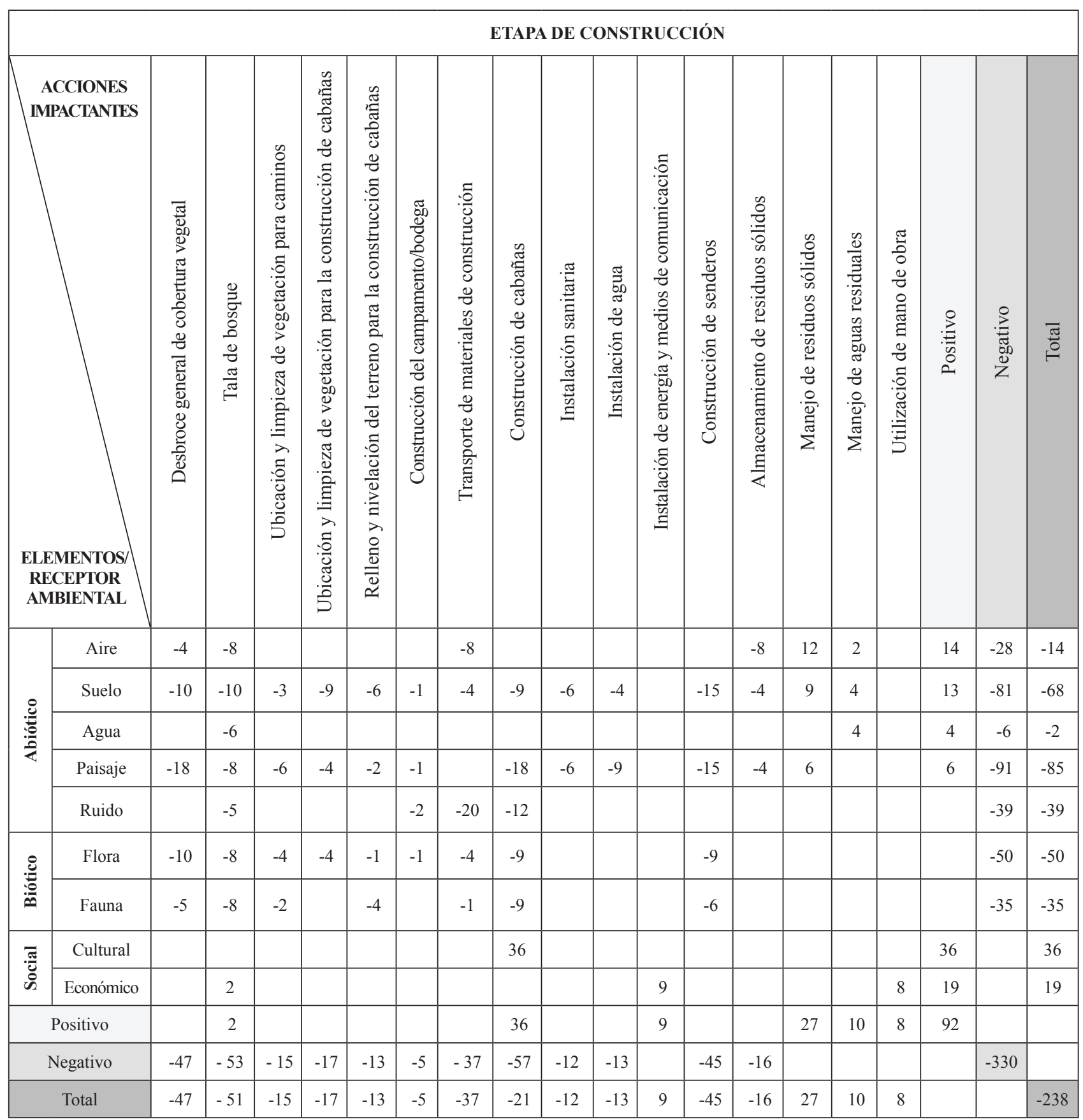

\section{Transporte de materiales de construcción}

- Elaboración e implementación de un protocolo para que los vehículos de transporte de materiales y almacenamiento sean ubicados en lugares distantes de los receptores sensibles (bosque prístino).

- Implementación de un cronograma y horario de operación de la maquinaria para reducir la perturbación a la fauna y calidad de aire.
- Implementación de normas básicas para la circulación vehicular a efecto de que sea regulada a lo largo de la vía utilizada, especialmente cuando se transite en sectores poblados

- Ejecución del mantenimiento periódico del equipo motorizado para maximizar la eficiencia de la combustión y minimizar la emisión de contaminantes y reducir el ruido a niveles aceptables. 


\section{Construcción de cabañas}

- Elaboración e implementación de un amplio programa de capacitación en temas ambientales y culturales.

- Implementación de políticas que aseguren la participación de mano de obra local durante la fase constructiva del proyecto a efecto de dinamizar la economía local.

\section{Conclusiones}

El diagnóstico ex ante o línea base conducido en el área general de implantación del proyecto muestra la pre-factibilidad ambiental de su ejecución, basándose en la extensión del área de intervención, la implementación en un sitio antrópicamente altamente modificado y que no alberga elementos bióticos endémicos y/o en peligro de extinción, exceptuando la pava de monte (Penelope jacquacu) cuyo potencial de afectación podría mitigarse con la implementación rigurosa y oportuna de medidas específicas de sensibilización a la población local.

En el área de influencia directa del proyecto, la identificación y valoración de impactos considerando los criterios de magnitud e importancia, señalan como

\section{Referencias}

Albuja, L., Almendáriz, A., Barriga, R., Montalvo, L., Cáceres, F. \& Román, J. (2012). Fauna de vertebrados del Ecuador. Editorial Escuela Politécnica Nacional-Instituto de Ciencias Biológicas, Quito, Ecuador.

Asociación Enrique Sanfiz (2016). Buscadores de oro: Bateo. Asociación de buscadores de oro Enrique Sanfiz, Navelgas, España.

Gobierno Parroquial de Misahuallí (2011). Plan del buen vivir y ordenamiento territorial de la parroquia de Puerto Misahualli 2011-2020. GPPM, Tena, Ecuador.

INAMHI (2014). Reporte INAMHI de las series 2008-2014. INAMHI, Quito Ecuador.

Izko, X. (2012). La frontera invisible: actividades extractivas, infraestructura y ambiente en la Amazonía ecuatoriana (2010 - 2030). IICA, Quito, Ecuador. impactos ambientales altamente negativos a la tala de bosque (-51), el desbroce general de cobertura vegetal (-47), la construcción de senderos (-45) y el transporte de materiales de construcción (-37). Por otro lado, también se encontraron impactos ambientales positivos, en especial la contribución del proyecto a la revalorización de la cultura a través de la construcción de cabañas vernáculas y la demanda de mano de obra que dinamizaría la economía local.

Dentro de la influencia indirecta del proyecto, existen impactos positivos de magnitud baja e importancia puntual por la recurrente demanda de mano de obra y la adquisición de materiales de construcción.

En la formulación de las medidas de manejo ambiental generadas por este estudio sobresalen aquellas orientadas a la mitigación/reducción de impactos ambientales que abarcan el $50 \%$ del total de medidas propuestas.

La identificación y valoración de los impactos ambientales permite concluir que es factible la ejecución del proyecto ecoturístico Shalcani desde la óptica ambiental si se considera seriamente la implementación de medidas de manejo que prevengan, mitiguen y compensen los efectos negativos al ambiente antes y durante la construcción de las cabañas.

Mittermeier, R., Goettsch, C. \& Robles, P. (1997). Megadiversidad: los países biológicamente más ricos del mundo. Cemex.

Peláez, J., 2002. Evaluación del impacto ambiental de proyectos de desarrollo. Universidad Nacional, Medellín, Colombia.

Vera, A. \& Riera, L. (2001). Desarrollo de actividades silvopastoriles para reahabilitar pastizales en la zona norte de la Región Amazónica ecuatoriana. INIAP, Quito, Ecuador.

Villavicencio, A. (2011). Valoración económica de la biodiversidad: experiencias en el Ecuador, en: Granizo, T. \& Ríos, M. (Eds.), Memorias del Seminario: Aprovechamiento económico del bioconocimiento, los recursos genéticos, las especies y las funciones ecosistémicas en el Ecuador. Ministerio Coordinador de Patrimonio. Quito, Ecuador, pp. 64-65. 